This is the Accepted Manuscript of an article published by Taylor \& Francis Group in Construction Management and Economics

Available online: https://doi.org/10.1080/01446193.2019.1593471

\title{
'Shared Sense of Purposefulness': A New Concept to Understand the Practice of Coordinating Design in Construction
}

\section{Mustafa Selçuk Çıdık ${ }^{1}$, David Boyd ${ }^{2}$}

\begin{abstract}
Construction management literature sees the collective task of coordinating design as being about the 'integration' of 'fragmented' discipline-specific design tasks/outputs, thus overlooking the important role of social interactions. This is not only conceptually problematic but also presents a practical management problem. As a response, a practice-based approach, which relies on a 'becoming' ontology, is adopted for a practical explanation of design coordination for more effective design management. The adopted methodology suggests that design develops as a result of unfolding (path-dependent) individual actions and interdisciplinary interactions. Based on this, the concept of a 'shared sense of purposefulness' is proposed to refer to the temporary and precarious organisational state of a design team in which each of the interacting team members has achieved a state of purposefulness to resume individual action. Hence, design coordination in construction is redefined as continuously reestablishing and maintaining 'a shared sense of purposefulness'. The concept's usefulness for understanding the practice of design coordination is demonstrated using data collected from a project in the UK. The discussion enables fresh insights into the everyday operation of design coordination. It is concluded that the proposed conception paves a way forward both for the research and practice in construction design management.
\end{abstract}

Keywords: design coordination, design management, sensemaking, organizational analysis, practice-based study, construction

\footnotetext{
${ }^{1}$ School of the Built Environment and Architecture, London South Bank University, UK

${ }^{2}$ School of Engineering and the Built Environment, Birmingham City University, UK
} 


\section{Introduction}

Design in construction requires coordination to assure the consistency and coherence between different discipline-specific parts of the design. What does such coordination involve? In construction management, both professional and academic literatures see 'design coordination' as primarily about 'integrating' the individual 'fragmented' parts of design tasks and outputs. Thus, these literatures focus on the differences between individual disciplines and project phases for managing coordination based on individual design tasks and/or outputs. This understanding is apparent in key practitioner documents, such as RIBA Plan of Works 2013 (Sinclair 2014), as well as in academic studies on design management and design technologies in construction, such as Baldwin et al. (1999), Kagioglu et al. (2002) as well as Bouchlaghem et al. (2005), and Ciribini et al. (2016). However, such an analytical view of coordination lacks an adequate consideration of the importance of social interactions, thus falling short in providing adequate insight on how coordination should be managed in practice. The present paper sets out to address that lack by introducing the concept of a 'shared sense of purposefulness' and providing a novel conception of design coordination in construction. A 'shared sense of purposefulness' refers to the temporary and precarious organisational state of a design team in which each of the interacting team members has achieved a sense of purposefulness to resume individual action.

The paper first reviews the design management literature in construction to establish the need for a novel conception of coordination which considers evolving social interactions as a key issue. It then discusses two different strands of literature which have highlighted the importance of social interactions in the multidisciplinary design process: one which treats social interactions as a matter of cognitive achievement or experiential learning (e.g. Kleinsmann et al. 2010, Dong et al. 2013), and another 
which adopts a practice-based view (e.g. Luck2012a, McDonnell and Lloyd 2014, Kasali and Nersessian 2015) that considers unfolding social interactions as the drivers of the evolving design. Drawing on the latter of these strands, the present paper subsequently puts forward the concept of a 'shared sense of purposefulness' and redefines design coordination as an ongoing process of mutual shaping between interdisciplinary interactions and the actions of individual practitioners. It demonstrates the concept's usefulness for understanding how design coordination is enacted in multidisciplinary design practices by using observational data collected from a project in the UK. Finally, it discusses the implications of this new conception for design management and design technology development in construction.

\section{'Coordination' in Construction Design Management Literature: The Missing Link to Social Organisation}

Design management literature in construction includes surprisingly few studies that build theory about how multidisciplinary design is socially organised; or how it is possible to manage the social process of coordination rather than managing individual design tasks. Some contributions (e.g. Koskela et al. 2002, Zerjav 2012) have criticized this lack of studies but do not develop a coherent theory addressing this social coordination process. As stated by Emmitt (2016), construction design management has only recently started to be seen as an encompassing function to address the growing complexities of coordinating and managing multidisciplinary design information for assuring overall design quality.

However, even the recent publications which adopt such an encompassing view of design management have not engaged in building theory that considers the social organisation as a key issue. They have rather focused on roles and tasks of the design manager at different stages of a building's lifecycle, thus still implying that the 
differences between various design disciplines and project phases is the core issue to be managed (Eynon 2013, Emmitt and Ruikar 2013, Emmitt 2016). These differences, generally referred to as 'fragmentation' (Nitithamyong and Skibniewski 2004, Elmualim and Gilder 2014), are generally associated with inefficiency in construction management literature (e.g. Latham 1994, Egan 1998, Nitithamyong and Skibniewski 2004). This so-called 'fragmentation' is also regarded as the central problem in construction design management (e.g. Kent and Becerik-Gerber 2010, Elmualim and Gilder 2014), which needs to be addressed through 'integration' (e.g. Love et al. 2004, Oh et al. 2015). The studies preoccupied with this 'fragmentation-integration' debate generally either interpret the empirical findings from construction design as a process of 'integrating' isolated and autonomous actors/entities, or conjecture about how design could be improved based on the pre-assumed structural challenges originating from ‘fragmentation’ (e.g. Kagioglou et al. 2000, Love et al. 2004, Oh et al. 2015). However, as Baiden et al. (2006) have shown, the notions of 'fragmentation' and 'integration' in research in construction must be subject to critical examination because the extent and characteristics of the required 'integration' to tackle the so-called 'fragmentation' are elusive, and involve joint consideration of several interdependent dimensions (social, economic, technological, etc.).

Zerjav (2012) criticises the analytical view of design coordination, which relies on the fragmentation-integration dichotomy, for being analytically reductionist, and so, resulting in ineffective management. This is supported by Cicmil and Marshall (2005), Dossick and Neff $(2010,2011)$, and Çıdık et al. (2017), who show that managerial actions and/or design support technologies, that do not acknowledge adequately the social complexity and flux in coordination, may be ineffective if not counter-productive in practice. Hence, Zerjav (2012) and Zerjav et al. (2013) suggest that, when managing 
design in construction, classic project management approaches, which assumes an analytical view of design coordination, must be abandoned. They suggest that interpretivist approaches focusing on everyday social interactions (see below) should be integrated into construction design management.

In response to these criticisms, research on construction design management has recently started to pay increasing attention to the social organisation of multidisciplinary design. Among them, the studies on 'lean design management' (Emmitt 2011, Fosse and Ballard 2016) acknowledge the criticality of social organisation; and some studies of lean design management attempt to consider social organisation by employing concepts such as 'organisational interdependencies' (Bølviken et al. 2010) and 'organisational power' (Knotten et al. 2015). However, these studies tend to engage in macro analyses of processes; and therefore, they fall short in enabling insights about the micro social processes that drive everyday design practices. By contrast, adopting a practice-based approach, Zerjav (2015) argues that, in construction design, the boundaries between the organisations that are involved in a project, emerge in practice as a result of unfolding social interactions. Therefore, what is needed for more effective management of design coordination in practice is a novel conception of coordination that considers evolving social interactions in a design team as a key issue. There are two strands of literature which highlight the importance of social interactions in multidisciplinary design, namely group cognition and practice based, and these are reviewed in the next sections.

\section{Social Interactions as a Matter of Group Cognition in Multidisciplinary Design}

A common theme in design research has been the idea that social interactions in multidisciplinary design enables a cognitive achievement or experiential learning, thus 
seeing the social interactions as the means to creating and/or integrating group knowledge (Kleinsmann and Valkenburg 2008). Hence, studies in this strand of literature mostly focus on isolated episodes of face-to-face interaction with the purpose of exploring how such a knowledge is generated and/or integrated. For example, Valkenburg (1998) studies a two hours long episode of design team meeting and concludes that "shared understanding is a mutual knowledge of all team members on what they are doing, why, and how they are doing it" (p. 120). Stempfle and BadkeSchaub (2002) study 6 hours long interactions of three laboratory teams to investigate how design teams deal with design problems with a focus on the cognitive processes of design teams during these interactions. Similarly, drawing on the 'reflective practice' paradigm (Schön 1983), Valkenburg and Dorst (1998) as well as Stumpf and McDonnell (2002) explore the experiential learning of design teams, based on detailed analyses of individual face-to-face design interactions. Dong et al. (2013) study 75 minutes long face-to-face interactions of nine different design teams that work on the same simulation in order to develop approaches to measure the 'quality' of the 'team mental model' as well as to develop insights into how such a mental model enacts in face-to-face interactions.

This literature also involves research that studies the role of particular acts and/or artefacts in enabling such a cognitive achievement or experiential learning. For example, Boujut (2003) studies the cognitive role of annotations, while Dijk and Lugt (2013) more generally look at the cognitive role of the jointly created (and used) artefacts, during design meetings for enabling 'shared understanding'. In a similar vein, Cash et al. (2017) study the influence of question asking and feedback on creating 'shared understanding' by comparing the conceptual maps of individuals before and after an online design meeting. By contrast, Kleinsman and Valkenburg (2008) 
longitudinally study the social interactions in design teams through case studies but they focus on the barriers and enablers of 'shared understanding' rather than analysing the process of the observed social interactions.

This body of work, however, does not consider how social interactions in a design team change over time. Thus, it falls short in explaining how coordination is enacted in practice through an ongoing stream of individual actions and interdisciplinary interactions that take place in a construction design project. More specifically, it is not clear from these studies, what triggers interdisciplinary interactions at any point in time, how preceding episodes of actions and interactions shape the subsequent ones, and how design practitioners know that they have arrived at a joint perspective so that they stop interacting and go about their individual design activities. Understanding these issues is critical for a practical conception of coordination because construction design develops as decisions unfold and events occur (Zerjav 2012). Hence, a conception of construction design coordination needs to consider social interactions as evolving while explaining how such evolving sociality enables progressive coordinated action amongst individual practitioners with different responsibilities and expertise. The evolving nature of design is acknowledged in practice-based view of designing and this literature is reviewed next.

\section{Social Interactions as the Driver of 'Becoming' Design (Practice-based View of Multidisciplinary Design)}

Practice-based studies of multidisciplinary design reject the idea that multidisciplinary design is merely a collection of isolated or individual creative activities. These studies variously use a practice-based approach and start seeing the importance of the continuously developing aspects of the task in relation to the evolving social situations within which the task is taking place. As explained by Luck (2012a), and demonstrated 
in Luck (2012b) as well as Oak (2012), a focus on the practice of "doing designing" (Luck 2012a, p. 521) reveals the importance of mundane, everyday social interactions among design stakeholders in enabling an intersubjective understanding about their situated design practice to move the design forward.

As shown by Oak (2009) and McDonnell (2009), when the focus is on the empirical details of interdisciplinary interactions, it becomes apparent that even the roles of, for example, building user, client and designer are continually negotiated during interactions. Hence, to some degree, they are emergent features of the unfolding social interactions, although a priori designations of the roles play their part. Therefore, as stated by McDonnell (2009), when attention is paid to the achievements of such mundane situated interactions, it becomes apparent that they address various issues at different levels of granularity regarding the organisation of the multidisciplinary work; and hence, they are essential for coordination. Thus, practice-based empirical studies of multidisciplinary design emphasise that it is such mundane formal and informal interactions that enable design stakeholders to move forward consistently in their design by providing a rich and multidimensional intersubjective understanding of how multidisciplinary work is organised. According to Van Amstel et al. (2016), such ongoing situated interactions dialectically produce the design space, which configures the logic of designing in a particular organisational context; and therefore, determine, what is possible/acceptable and what is impossible/unacceptable to design.

On the other hand, as shown in the works of Cross and Cross (1995), Eckert et al. (2013), Van Amstel et al. (2016) and Aaltonen et al. (2017), this does not imply that design is happening in an entirely unchartered environment but involves some enabling structures that create a basis for the situated interactions mentioned above. As these studies show, design stakeholders bring into their practices a priori templates for 
exploration, communication and/or organization that are formed through past experiences of similar negotiated and situated contexts.

Ultimately, a practice-based account suggests that multidisciplinary design can be seen as a negotiated process of organisational becoming (Cicmil and Marshall 2005, Dossick and Neff 2011). In this process, the structure, as enacted through the 'normal' practices brought to the project by design stakeholders, and the agency of individual disciplinary roles, as enacted in interactions in the unique situated contexts, are continuously forming and being formed by one another through interdisciplinary interactions. According to Cicmil and Marshall (2005), who cite Stacey (2001, 2003), it is this continuous mutual shaping that creates new patterns of routines and habits, and new representation of emerging reality, shared by an interacting group.

Nevertheless, although practice-based view of multidisciplinary design suggests that agency is not an individual property because it is largely directed by group interactions, this literature does not provide much insight regarding the practical mechanisms of the interplay between individual action and group interactions in practice. This aspect is addressed by the sensemaking perspective (Weick 1995, Weick et al. 2005) through which the concept of 'shared sense of purposefulness' was developed in order to explain how coordinated action of individual designers is possible in construction design practice.

\section{'Shared Sense of Purposefulness' as the Essence of Coordinated Design Action}

The 'sensemaking perspective' (Weick 1995, Weick et al. 2005) aligns with a becoming view of design, and explains how social construction of emerging reality is key for interacting groups to become an 'organisation'; or to act in a coordinated manner. Weick et al. (2005) claim that organising is the response to "an ongoing, unknowable, 
unpredictable streaming of experience in search of answers to the question 'what is the story?"” (p. 410). This response involves collective negotiations for "turning circumstances into a situation that is comprehended explicitly... and that serves as a springboard into action" (Weick et al., 2005: 409). Thus, according to the sensemaking perspective, in the flux of events in an organisation, plausible stories animate and gain their validity from subsequent activities (Weick et al. 2005).

This thinking leads to the argument that in a multidisciplinary design team, individual practitioners stay in (design) action as long as they feel that they have a plausible story of 'what is going on' to direct their actions. Importantly, here, they judge 'plausibility' of their own story based upon their ongoing interactions with the other team members (e.g. talking to them, reviewing their work etc.). Thus, an individual's plausible story of 'what is going on', which relies on interdisciplinary interactions, enables and directs individual action by creating an individual state of purposefulness. We call this individual state of purposefulness a 'sense of purposefulness' in order to highlight that it depends on how an individual made sense of 'what is going on'. Hence, this paper proposes the concept of a 'shared sense of purposefulness' in order to capture the organisational state of a design team in which all the interacting parties has achieved a 'sense of purposefulness' that enable individual action. This corresponds to the state in which the interacting design practitioners have their own plausible stories about 'what is going on' aligned with others to enable individual design action. As a result, it is argued that establishing a 'shared sense of purposefulness' is the necessary and enough condition to enable coordinated action in a design team.

Additionally, the sensemaking perspective subscribes to the wider phenomenological assumption that the default mode of experience of practitioners is the experience of immersion which lasts as long as their action flows as they expect, but 
they switch to a different, discovery-focused experiential mode as soon as something unexpected disrupts their action (Heidegger 1962). This means that "explicit efforts at sensemaking occurs when the current state of the world is perceived to be different from the expected state of the world, or when there is no obvious way to engage the world" (Weick et al. 2005 p.409). Importantly, to make sense of the disruption, practitioners first look for explanations of 'what is going on' based on the available social (e.g. traditions, acceptable justifications etc.) and material (e.g. plans, instructions etc.) cues to resume the interrupted action and return to the experience of immersion (Weick 1995). These arguments provide an explanation of why multidisciplinary design projects witness an ongoing but interrupted stream of explicit negotiations. According to this, we will show that explicit negotiations around design issues occur to re-establish a 'shared sense of purposefulness' when one or more practitioners' 'sense of purposefulness' is somehow disrupted.

Therefore, we argue that coordination is essentially about (re-) establishing and maintaining a 'shared sense of purposefulness' for the resumption of practitioners' design actions. This view acknowledges the continuity, evolution, and path-dependency of design practices, thus providing a conception of coordination that considers both individual actions and interdisciplinary (i.e. social) interactions in a design team as continuously evolving in relation to each other.

\section{Methodology}

\section{Theoretical Orientation}

In order to explore the concept of a 'shared sense of purposefulness' in construction design, a methodology that acknowledges the phenomenological and organisational aspects of design was adopted. Following the practice-based tradition in design 
research, this paper adopts a becoming ontology (Cicmil and Marshall 2005, Langley et al. 2013). According to this, entities are merely instantiations of ongoing processes; and therefore, they are continually in a state of 'becoming' (Tsoukas and Chai 2002).

Langley et al. (2013, p. 5) emphasise that "changing in this view is not something that happens to things, but the way in which reality is brought into being in every instant". From this perspective, the reality is constituted by events (Langley et al. 2013), rather than universal categories of entities such as 'design', 'designer', 'design task' or 'design outputs' as the analytical approach to coordination assumes. Each event/practice arises out of, and is constituted through, its relations to other events within a continuous flux of path-dependent becoming. Therefore, key to this approach, is a relational epistemology (Emirbayer 1997) that suggests that entities relating to design practices must be understood by the web of relations that enact them in certain ways within a particular flux of becoming rather than through decontextualized and abstract explanations. Hence, multidisciplinary design, like any other practical undertaking, consists of a set of empirically observable, unfolding and path-dependent interactions in practice which continuously re-configure designers' understandings about design situations, and thus driving them to act in certain ways (i.e. enacting their agency in certain ways).

\section{Analytical Orientation}

This research was conducted as part of a wider practice-based, workplace study (Jordan 1996) that explored the enactment of 'organisational order' in three Building Information Modelling (BIM)-enabled construction design projects that were at different stages of design. The data collection, analysis and texts of this wider study were in line with ethnomethodological ethnography (Gubrium and Holstein 1997) which involved ethnomethodological analyses (Schutt 2011, Nicolini 2012) of the three 
projects to reveal the ways in which design practitioners in construction made sense of their work by focusing on their actions and interactions. Therefore, a key component of the analysis was the constant revisits to literature for finding conceptual and theoretical fixes between the literature and the aggregating empirical data. Concepts and theories from the literature, such as 'sensemaking' (Weick 1995, Weick et al. 2005), certainly affected the nature of the fieldwork and the desk inquiry, but in a way which increased the need to look closer at certain aspects of the data and practice, rather than adopting fixed conceptual categories to be filled with data. In this regard, the data analysis and data collection went hand-in-hand, and the theory development was progressive, similar to grounded theory development explained in Gioia et al. (2013).

In this process, the concept of 'shared sense of purposefulness' surfaced as a useful concept from attempts to explain why, how and when design practitioners interact with each other and with what effect; as suggested by the sensemaking literature (Weick 1995, Weick et al. 2005). The concept resonates with the fundamental assumption of sensemaking perspective that practitioners invent plausible stories about their stream of experience, and act upon their story of 'what is going on' (Weick 1995, Weick et al. 2005). The concept reflects the social aspect of the design activity in the idea of sharing. On the other hand, it also acknowledges the significance of individual agendas, interests and foci through the purposefulness that is set up and the idea that this is derived from sensing (not only the explicit cues but also being sensitive to the history and the context). Overall, the concept helps explaining how practitioners, who have different backgrounds, interests and expertise within a multidisciplinary design team, make sense of the continuous flux of the evolving design, and manage to progressively develop coherent and consistent design outputs. It is an intermediate concept (Bebeau and Thoma 1999) in the sense that it comes from abstract theory but 
expresses practice in a way that is generally understandable and so useful for engaging in change. Not being fixed, it is adaptable and developmental, thus making it more useful for different people in different circumstances. Ultimately the concept enables a definition of coordination as unfolding as it suggests that coordination is continuous (re)establishment and maintenance of a shared sense of purposefulness within a negotiated 'organisational-becoming-process'.

Although the proposed view of coordination and the concept of 'shared sense of purposefulness' were apparent across the three studied projects, the educational building project, which was at its detailed design stage, is selected to be used for their demonstration in the present paper. This is because the educational building project included events where the effect of path-dependency was most obvious in interdisciplinary interactions of the practitioners, of which two are presented. The first author passively observed the interdisciplinary design interactions in this educational building project for 10 months by attending 23 interdisciplinary meetings including regular design coordination meetings, one-off design coordination workshops as well as clash-detection and information-model coordination meetings. Each meeting lasted between 1-1.5 hours except one coordination workshop which was a day-long activity. In line with the aim of the larger study, the observations reported in this study explored both the overall process of the unfolding coordination activities and the details of situation-specific interactions that took place in the observed activities. Audio and video recordings were not allowed. The observational data were recorded in field notes, and the researcher's reflections on 'what is going on' was mainly supported by informal communications with the participants that took place right before, right after and/or during the breaks of the meetings. Additionally, five semi-structured interviews were conducted at the fourth month of the observation period with the representatives of the 
architect and mechanical and electrical engineering consultant who were involved in the design from the beginning of the project. The interviews had two main aims. First, to gain a deeper insight into the historical development of some of the issues that were repeatedly discussed in the observed meetings. Second, to develop an understanding of the unobserved, remote interdisciplinary interactions going on in the project including model-based interactions. The interviews were transcribed and considered together with the observational data that had been accumulating, thus supporting the researcher's understanding of 'what is going on' in the observed project from the practitioners' perspective.

\section{Coordinating Multidisciplinary Design in Practice}

The unfolding view of coordination will be demonstrated through the descriptions of the coordination activities in a construction design project at two different levels of organising. First, at the project-level, the path-dependency of coordination activities will be described considering how the range and scope of coordination activities evolved over the ten-months-long period of observation, thus providing a macro view of design coordination as an unfolding process of becoming. Second, at the practice-level, two events from design coordination meetings will be described to demonstrate the role of 'shared sense of purposefulness'. This will reveal how social interactions at micro level build upon previous actions and interactions to re-establish a joint perspective on the design task and enable subsequent episodes of coordinated individual design action.

\section{Unfolding Scope and Range of Interdisciplinary Interactions at Project-level}

In the observed project, there were a variety of interdisciplinary interactions. Most formal were regular design-coordination meetings (DCM) that were set up by the design-build main contractor. These, in theory, were to communicate and/or make 
definite decisions about the design; however, most episodes of discussion were concluded by agreeing on some action points involving further remote interactions, such as commenting on, or marking-up some design documents related to the topic of discussion. In such cases, face-to-face discussion of an issue (e.g. ventilation of the ground floor) complemented remote interaction about more-detailed aspects of that issue (e.g. reviewing the schedule of outlets on the ground floor) and vice-versa (e.g. review of the schedule of outlets led to a further need for face-to-face discussion regarding the type of the outlets on the bulkheads in the reception area). Moreover, practitioners employed various modes of face-to-face interaction based upon their perceptions of both the issue and the suitability of the previously established means of interaction for the evolving needs. For example, when the rate of installation on the site increased the design team decided to increase the frequency of formal group site visits, which in turn affected the scope of Design Coordination Meetings (DCMs) by increasing the number of references made to site visits during the interactions in DCMs. Also, they would informally 'catch-up' with each other over a quick chat in different occasions, such as while preparing their coffees, by asking questions like 'did you see my email about the loading bay'. Overall, 'coordination' consisted of a range of face-toface and remote modes of interaction which continuously unfolded on each other in relation to the evolving perceptions of practitioners regarding what needed to be done next.

Significant in this evolution was the heavy influence of individual professional and group shared past experiences which set mutual expectations among various practitioners. Based upon their individual professional experiences, practitioners knew that they would have to deal with evolving types of issues using an evolving range and scope of interactions. Also, most of the time, they knew about the kinds of issues that 
they would have to deal with at a particular stage of the design process, and the modes of interactions they could potentially use to deal with them. For example, although designing a learning space meant different things to the architect and M\&E engineers in the observed project, they both knew that the positions of audio-visual equipment needed to be coordinated with the planned locations of the furniture and electricalmechanical services at the detailed design stage based on their past professional experiences. Shared past experiences were not any less influential in setting mutual expectations among various practitioners. For example, conversation openers like 'do you remember our conversation about the bulkheads in the reception area' were frequently used to start discussing a certain issue in the observed meetings. This revealed how designers collectively progressed the meaning of 'unresolved issues', thus setting mutual expectations about what is needed to be done next.

Importantly, mutually expected issues did not occupy much time to be established and/or action-planned in the observed interdisciplinary interactions. However, unexpected and differently expected, or in other words 'disrupting', issues took much more time and effort to be established and action-planned. Indeed, the agenda structure of regular DCMs, which consisted of two sections (i.e. 'previous minutes' and 'updates' sections), reflected this important difference. Negotiations of the items in the 'previous minutes' section would take the majority of time spent in a DCM in order to make sense of, and plan for, the unexpected or differently expected issues that were discovered. Whereas, the 'updates' section would be gone through very quickly as it mainly included mutually expected issues such as information and meeting requests between disciplines typical to that stage of design, updates about work-inprogress for each discipline, and so on. As a result, interdisciplinary interactions evolved in the face of a mixture of mutually expected, differently expected, and 
unexpected, needs for interacting. Thus, maintaining a progressive sense of what to do in discipline-specific work depended on participating in these evolving interdisciplinary interactions.

\section{Nature and Flow of Interdisciplinary Interactions at Practice-level}

\section{Event 1:}

All the areas in the building, apart from the atrium, were serviced through suspended ceilings. This was a very conventional system for such buildings, therefore the architect, the $M \& E$ consultant, and the $M \& E$ sub-contractor were experienced in their design and installation, and there were agreed design strategies in the project for working with them. However, for the board room, the client briefing stated that "the ceiling in board room will be different" and in the end the architect specified a decorative wooden ceiling. This had serious implications on several other systems, thus, this single irregular ceiling type required much following coordination. For example, the chilled beams that were specified for the board room surfaced as a major issue. The complexity of the decision involved: the fixing details of both wooden ceiling and chilled beams, the efficiency of chilled beams when placed above the wooden ceiling, the laying direction of the individual wooden pieces and chilled beams, and the colour of wooden ceiling and chilled beams (because the chilled beams would be visible from the gaps between wooden pieces). These issues all needed to be discussed as part of the 'previous minutes' in the following DCMs between the architect who was responsible for the ceiling, the M\&E consultant who specified chilled beams for that space, and the M\&E sub-contractor who were supposed to deliver detailed design and do the installation. 
First of all, it is important to state that before this issue was first raised, discipline-specific designs concerning the suspended ceilings were ongoing without a need for any explicit or lengthy discussions during the DCMs. Hence, there was an already established 'shared sense of purposefulness' that had been maintained (i.e. reconfirmed) by practitioners' ongoing validation of their stories of 'what is going on' through, for example, informal conversations, e-mails exchanges, document reviews or during the short 'updates' section of the DCMs. Until the representative of the M\&E sub-contractor raised the exceptional case of the boardroom ceiling in a DCM, these regular re-confirmation acts of a 'shared sense of purposefulness' avoided the need for effortful and time consuming explicit interdisciplinary interactions regarding the design of the areas with suspended ceilings. However, the irregular instance of wooden suspending ceiling in the board room disrupted the expected flow of activity and required further interactions to invent a plausible story regarding 'what is going on'.

This issue then was not a mutually expected one. It was first raised by the representative of the $M \& E$ subcontractor because he did not know how to go about it, or in Weick et al.'s (2005) words, he had 'no obvious way to engage the world'. Strikingly, when the representative of the M\&E sub-contractor first raised the issue, he first wanted to learn the story behind the initial decision as his organisation had joined the project recently for doing the detailed design and installations. He tried to establish whether the wooden ceiling was particularly specified by the client or the client only specified a different type of ceiling for which the architect had decided to have wooden ceilings. Once it was revealed that it was the client's decision, then the practitioners built their own stories upon this initial baseline story by discovering the available cues, or in other words by identifying the points that they thought would require further interactions, such as the fixing details of wooden pieces and chilled beams, as 
mentioned above. Ultimately, these unfolding interdisciplinary interactions continuously re-established 'a shared sense of purposefulness' which enabled progressive coordinated activity regarding the design of the ceiling in the boardroom.

\section{Event 2:}

At the beginning of the detailed design stage, the design changed significantly, at the request of the client to increase the total net internal area of the building. This had critical impact on the need for, and scope of, practice-level interdisciplinary interactions. Although the previous service and architectural strategies were reviewed as much as possible before the confirmation of the design change, some areas of the design had to be coordinated separately as they fell out of these general strategies. One example of this was about the servicing problems of the rooms in the corners on the floors above the ground level. The main servicing strategy for these floors was to pass the main services along the corridors on each floor, and distribute them into the rooms that open to the corridor. However, the rooms that were in the corners of each floor required additional coordination because they were in remote positions (i.e. largely isolated from the corridors) and their servicing needed to be specifically coordinated due to the number of the services that would have to pass through a very limited space. This issue stayed as an outstanding issue in 'previous minutes' section of DCMs for long time as detailed drawings by the architect and the M\&E sub-contractor were needed before the coordination could be done at the desired level of detail.

Here it is apparent that the design team's initial approach to the servicing of the rooms favoured the resumption of individual action by setting a general design strategy, or consistent individual stories of 'what is going on', that addressed majority of the rooms. This avoided further effortful and time-consuming explicit interdisciplinary interactions for the coordination of the services into the majority of the rooms which 
were along the corridors. Nevertheless, these interactively formed individual stories of 'what is going on' did not make sense for the servicing of the rooms in the corners due to the irregularities that they exhibited. Upon the notification of the issue with the corner rooms, the animated plausible story about this issue was that the practitioners needed to know more details about the design of the rooms and corridors before designing the services from the corridors into the corner rooms. This implies that altering the design to eliminate the corner rooms was not even an option as it would mean even more disruption disabling the progression of the design activity. Therefore, the decision to wait was the part of coordination of the servicing design of the corner rooms, and it was based on the 'shared sense of purposefulness' that was established at that point in time. Strikingly, once the practitioners deemed that the design was developed enough, they decided to interact with each other for negotiating the servicing of only one of the rooms in the corner. They judged that this would be enough to design the other rooms in the corners on various floors without further interdisciplinary interactions.

This suggested that establishing a 'shared sense of purposefulness' was the necessary and sufficient condition for enabling individual discipline-specific designs to progress in consistency and coherence with the others, as it gave all participants the necessary opportunity to make sense for themselves of their task and risk within a collectively negotiated frame of evaluation. It is in this sense that a 'shared sense of purposefulness' corresponded to a temporary and precarious state, which emerged based on the relational circumstances revealed through negotiations in regard to the issue at hand. As the event demonstrates, 'shared sense of purposefulness' is temporary and precarious because it only lasted as long as individual practitioners could confidently make sense of the unfolding situations based on their past experiences. 


\section{Discussion}

Luck (2012a, p. 521) argues that the study of design needs "a strong sense of 'the social""; however, this has not been translated into a conception of how to coordinate multidisciplinary design in construction, which has been left merely as an analytical integration of information or a rationalist management task. This lack of conception constrains the understanding of coordination and prevents adequate management of construction design. This study has shown that adopting a 'becoming' ontology resolves this problem by considering multidisciplinary design coordination as continuously unfolding through individual actions and interdisciplinary interactions. This discussion will build a theory of multidisciplinary design coordination that is centred upon maintaining a 'shared sense of purposefulness' by considering the path-dependency of interdisciplinary interactions as a key issue. The implications of this on construction design management and the development of digital design technologies, which are increasingly used to facilitate design coordination and management, will then be inferred.

\section{Redefining Multidisciplinary Design Coordination in Construction}

The project-level description has highlighted the continuous and path-dependent nature of interdisciplinary interactions in construction design. It emphasized that interdisciplinary interactions for coordination should not be seen as isolated events of design integration but rather as evolving in range and scope as a result of practitioners' path-dependent understandings of 'what is going on', and so, 'what needs to be done next'(i.e. sense of purposefulness). The description at the project-level also revealed that more (e.g. heated discussions in DCMs) and less (e.g. reviewing others' design outputs, nodding in DCMs etc.) explicit interdisciplinary interactions are equally 
important in enabling coordinated activity as they build upon each other, and so, reconfiguring each other on an ongoing basis. Nevertheless, significant in the projectlevel description is the criticality of the 'expectedness' of the faced issues which is the effect of a 'shared sense of purposefulness'. Hence, as the project-level description exposed, in practice, it is 'expectedness' which determines whether an issue is addressed through more explicit and effortful interactions, or passed quickly through less explicit and quick interactions.

The events presented in the data reveal that practitioners relied on two major kinds of resources to judge the 'expectedness' of a design issue within the flux of unfolding events. These were (i) previous professional experiences of individuals, and professional and institutional standards of their practice; and (ii) the jointly constructed shared past of interdisciplinary interactions in the project itself. These two kinds of resources enabled practitioners to come up with consistent plausible stories of "what is going on' and 'what needs to be done', which were collectively articulated as a 'general design strategy'. The first kind of resource, previous professional experiences of individuals, and the professional and institutional standards of their practice, provided a core repertoire and guidelines for where to look and how to operate when judging the 'expectedness' of a design issue. Thus, it corresponds to what previous practice-based studies referred to as enactment of 'structure' in practice, and a priori templates brought to the practice by practitioners. In Event 1, for example, until the described disruption, detailed architectural and M\&E designs were proceeding as 'expected' and the representatives of the $\mathrm{M} \& \mathrm{E}$ sub-contractor and the architect did not need to engage in lengthy explicit interactions on the details of various instances where conventional suspended ceilings were involved. This was because both of the interacting parties had substantial previous experience of working with this conventional building system, and 
so, they could develop detailed designs to allow the design to proceed as 'expected' without any further clarifications. This also suggests that the representatives from both disciplines had mutual expectations regarding what the detailed design of the other party should consider, which reveals that they had a mutual understanding of the task in hand enabled by professional and institutional standards of their practice. Besides, equally important in judging the 'expectedness' of issues was the second kind of resource, the jointly constructed shared past of interdisciplinary interactions in the project itself. This gave a joint appreciation of what led to the present, thus progressing a collective understanding of what can be seen as 'expected', and what cannot be seen as such and needs to be the subject of more explicit interdisciplinary negotiations. This is evident in Event 2 where the judgement of 'expectedness' was largely based upon the previously established 'design strategy' for servicing the rooms. As exposed by the event, such a shared past created a remarkable efficiency in discipline-specific decisionmaking by providing a collectively agreed 'strategy' which reconciled expectations of multiple practitioners.

The events also reveal why judging the 'expectedness' of the flux of events was key in determining the way in which interactions unfolded. The findings suggest that such a judgement was key because it indicated whether a practitioner's individual story of 'what is going on' (sense of purposefulness) was still plausible (i.e. valid) or needed to be fixed (i.e. re-established). As observed in both events, as long as the 'general design strategy' was undisrupted, practitioners did not need further explicit and effortful interactions. They were still, for example, reviewing each other's design outputs but did not feel a need for explicit interactions because what they reviewed was expected, thus validating their sense of purposefulness on an ongoing basis. However, when their stories of 'what is going on' were disrupted due to irregular instances which were 
unexpected or differently expected, this meant a need for more explicit interactions for coordination. This corresponded to a state in which the world that was perceived was different from the expected state of the world, or there was no obvious way to engage the world (Weick et al. 2005). Once each individual re-established a story of "what is going on', and therefore a sense of purposefulness, through explicit negotiations, the group then reached a 'shared sense of purposefulness' followed by a new episode of coordinated action. Ultimately, this suggests that, from a practice-based point of view, design coordination in construction can be redefined as continuously re-establishing and maintaining 'a shared sense of purposefulness'.

Importantly, during the explicit negotiations for re-establishing a 'shared sense of purposefulness', practitioners again relied on the same two kinds of resources upon which they judged the 'expectedness' of the flux of events (see above). So, when an unexpected or differently expected issue was discovered, negotiations relied upon the past individual professional experiences, and professional and institutional standards of practice, as well as the shared past in the project itself. For example, during the negotiations in Event 1, the representatives of the architect expressed their aesthetical concerns whereas the representatives of the $\mathrm{M} \& \mathrm{E}$ contractor talked about the cooling performance of the chilled beams. This suggests that individual professional experiences, and professional and institutional standards of practice, provided an initial repertoire and a template for such explicit negotiations by suggesting who should do what while trying to re-establish a sense of purposefulness. Besides, the jointly constructed shared past in the project itself, was also crucial in these negotiations. In Event 1, the representative of the $M \& E$ contractor first wanted to learn what happened previously in the project in relation to the board room with wooden ceilings; and in Event 2, the issue with the corner rooms was mainly negotiated in terms of the 
previously established design strategy for servicing the rooms. So, by enabling a joint appreciation of what led to the present, the shared past in the project significantly reduced the space of potential ways forward that would be acceptable to the parties involved, thus creating efficiency in interdisciplinary interactions based on a projectlevel path dependency.

In line with previous practice-based studies of multidisciplinary design, this paper suggests that design outputs, interfaces and possibilities are all dialectically constructed (Van Amstel 2016) by the means of evolving social interactions, but this paper further elaborates this assertion through an explanation of the empirically observable practical mechanisms of this co-construction process. According to this explanation, individual practitioners autonomously establish and validate plausible stories of 'what is going on' but these stories are coherent and consistent because they rely upon certain cues that are collectively noticed and bracketed through explicit interdisciplinary interactions. Here 'noticing' refers to highlighting certain cues by bringing them to attention and making them explicit, and 'bracketing' refers to attaching a particular significance to a certain cue (Weick et al. 2005). As discussed above, in the observed project, these cues were drawn from individual experience, professional and institutional standards of practice, as well as the shared past in the project itself, to varying extents, depending on their perceived relevance to the issue in hand. Significant in this explanation is the role of the cues that are noticed and bracketed as a group because they drive the plausibility of individual stories in certain ways, thus are key to setting the meaning of what is expected and what is disruptive for the following interactions. Importantly, this explanation of design coordination then implies that those who have more power (e.g. due to the possession of specific knowledge, authority, charism, communicational means, and so on) to notice and/or bracket the cues, or in 
Thomas's (1923) words to 'define the situation', would have an asymmetrical advantage to determine the direction of further interactions and design outputs.

\section{Managing construction design based on an unfolding view of coordination}

There has been no clear approach to, or school of, construction design management with a consistent body of research and/or practices for the practical management of multidisciplinary design. For years, the debate has been dominated by the problematic concept of design collaboration. Although 'collaboration' signifies the crucial importance of 'collectivity' and its 'organization' in multidisciplinary design, there has been discontent about the usefulness of the term in producing knowledge for practical management. Hence, construction design management methods and approaches as well as design support technologies have mainly been relying on a fragmentation-integration view of design organisation that does not adequately consider the sociality inherent in design practice. As a result, particularly on the technology side, several empirical studies have revealed the need for practically relevant theories of design coordination by exposing that collective working could be hampered when the logic of managing coordination is not aligned with the logic of the social organisation of design work (Kvan 2000, Dossick and Neff 2010, Whyte 2013, Çıdık et al. 2017).

The adoption of an unfolding view of coordination helps to address these shortcomings in design management and design technology development. First of all, it becomes apparent that design coordination is not an isolated function in design work that is accomplished during individual episodes of interdisciplinary interactions. Rather, it is an ongoing accomplishment that is achieved in, and through, all the various practices involving multidisciplinary design including both individual design actions and interdisciplinary interactions. Therefore, design coordination is path-dependent, unfolding and evolving, thus meaning different things and taking different forms at 
different points in time. This suggests that the focus of design management in construction should shift away from 'integrating' 'fragmented' design outputs to facilitating everyday interdisciplinary design interactions. Managerial efforts must acknowledge that these interactions are part of a wider and ongoing organisational effort for establishing and maintaining a 'shared sense of purposefulness' required for coordinated activity which does not necessarily need close-coupling of design practitioners. This novel conception of design coordination then also means that design management cannot be considered as a separate function performed by distinct 'design managers' that regulate the creative activities anymore. Rather, it is an integral part of designing because, in practice, the activities of managing and developing design are interacting parts of the same organizational whole.

In this context, collaborative design technologies in construction, such as building information modelling software, must also be transformed to support practitioners in establishing and confirming a 'shared sense of purposefulness'. This implies that the focus of collaborative technology development must shift away from integrating every possible piece of design data, to developing digital environments that can support people in their interactions by helping create a shared sense of purposefulness. Although still a challenge to accomplish in practice, previous research on human-computer interaction (e.g. Arias et al. 2000, Fischer et al. 2005) and computer supported cooperative work (Mills 2017) provide a starting point for moving towards such digital environments in construction design. Moreover, this paper suggests that the current trend of promoting the replacement of face-to-face interactions with remote interactions through digital means must be re-evaluated. Supporting design collaboration cannot be conceived separately from supporting the establishment of a shared past through continuous interdisciplinary interactions. Therefore, exchanging 
digital models between design practitioners without conscious planning for other kinds of interactions would not help collaboration and could even be harmful to collaboration.

\section{Conclusions}

The central role of social interactions for design teams has been emphasized both by studies that adopt a cognitive, and those that adopt a practice-based view of multidisciplinary design. However, design coordination in construction has mainly been seen as a matter of integrating the separate fragmented parts; and hence, the methods and approaches for managing construction design have mostly relied on traditional rationalistic project management underpinned by analytical reductionism. This is not only conceptually problematic but also presents a practical management problem. In an effort to address these shortcomings, the present paper has developed an unfolding (i.e. becoming) view of multidisciplinary design coordination centred upon the unfolding of individual actions and the interactions between various members of the design team. The centrality of enabling a 'shared sense of purposefulness' in this conception shifts the theorization of multidisciplinary design coordination away from a matter of situated problem-solving to one of continuous organizational capability building, and thus also shifts the priorities of construction design management and design technologies away from managing design tasks/outputs to managing organisational structures and interactions.

Under the proposed view, the ultimate question for multidisciplinary design management then becomes how the organizational capability for effectively identifying and using the means and processes of sensemaking can be developed through interventions at personal, professional, project, firm, and industry levels. As shown by this paper, professional and institutional standards of practice as well as the material and social spaces for interdisciplinary interaction are the two crucial focus points for 
enabling collaborative design in construction. Therefore, although the current design standards, templates, and guidelines are important resources for enabling interdisciplinary interactions, there is a need for readjusting them by recognizing that they must be tailored for facilitating interactions rather than giving instructions. Besides, the construction industry must recognize at all levels of its organisation that creating the adequate environment for design practitioners to jointly construct a shared past is of utmost importance for successful design, especially when there are unconventional and/or irregular aspects in the design, initially or due to changes.

This paper constitutes an important step forward for actuating these improvements in construction design management by enabling a starting point for developing practically relevant scholarship on construction design management against the backdrop of the studies that criticized the confusion around, and the lack of theory on, design management (Koskela et al. 2002, Johansson and Woodilla 2011, Zerjav 2012, Emmitt 2016). Future studies will need to build upon the conception proposed herein by engaging in further systematic analyses of construction design practices using the organisational sensemaking perspective, and hence, deliver comparable results in order to build rigorous design management theory. Initially it would be valuable to explore the various processes and means of sensemaking employed in construction design practices and their respective effectiveness in enabling a 'shared sense of purposefulness' in different types of settings and contexts. Findings of such research would not only help defining construction design management as a research discipline but would also facilitate a conversation between the various stakeholders of construction design practices to improve the practical management of design with a serious consideration of, sometimes not so obvious, power dynamics of design practices. 


\section{Acknowledgements}

The authors thank Ms. Maren Rohe for her comments on an earlier version of the manuscript. The authors also thank the anonymous reviewers and the editors for their help in refining this paper through their constructive comments.

\section{References}

Aaltonen, K., Ahola, T. and Artto, K., 2017. Something old, something new: path dependence and path creation during the early stage of a project. International journal of project management, 35 (5), 749-762.

Arias, E., Eden, H., Fischer, G., Gorman, A. and Scharff, E., 2000. Transcending the individual human mind — creating shared understanding through collaborative design. ACM transactions on computer-human interaction (TOCHI), 7 (1), 84113.

Baiden, B. K., Price, A. D. and Dainty, A. R., 2006. The extent of team integration within construction projects. International journal of project management, 24 (1), 13-23.

Baldwin, A.N., Austin, S.A., Hassan, T.M. and Thorpe, A., 1999. Modelling information flow during the conceptual and schematic stages of building design. Construction management and economics, 17 (2), 155-167.

Baudains, P., Bishop, S., Duffour, P., Marjanovic-Halburd, L., Psarra, S. and Spataru, C., 2014. A systems paradigm for integrated building design. Intelligent buildings international, 6 (4), 201-214.

Bebeau, M. and Thoma, S., 1999. "Intermediate" concepts and the connection to moral education. Educational psychology review, 11 (4), 343-360.

Bouchlaghem, D., Shang, H., Anumba, C.J., Cen, M., Miles, J. and Taylor, M., 2005. ICT-enabled collaborative working environment for concurrent conceptual design. Architectural engineering and design management, 1 (4), 261-280.

Boujut, J. F., 2003. User-defined annotations: artefacts for co-ordination and shared understanding in design teams. Journal of engineering design, 14 (4), 409-419.

Bølviken, T., Gullbrekken, B. and Nyseth, K., 2010. Collaborative design management. In: Proceedings of the 18th annual conference of the international group for lean construction, Haifa, Israel. 
Cash, P., Dekoninck, E. A. and Ahmed-Kristensen, S., 2017. Supporting the development of shared understanding in distributed design teams. Journal of engineering design, 28 (3), 147-170.

Cicmil, S. and Marshall, D., 2005. Insights into collaboration at the project level: complexity, social interaction and procurement mechanisms. Building research and information, 33 (6), 523-535.

Ciribini, A.L.C., Ventura, S.M. and Paneroni, M., 2016. Implementation of an interoperable process to optimise design and construction phases of a residential building: a BIM pilot project. Automation in construction, 71, 62-73.

Cross, N. and Cross, A. C., 1995. Observations of teamwork and social processes in design. Design studies, 16 (2), 143-170.

Çıdık, M.S., Boyd, D. and Thurairajah, N., 2017. Ordering in disguise: digital integration in built-environment practices. Building research and information, 45 (6), 665-680.

Dong, A., Kleinsmann, M. S. and Deken, F., 2013. Investigating design cognition in the construction and enactment of team mental models. Design studies, 34 (1), 1-33.

Dossick, C.S., and Neff, G., 2010. Organizational divisions in BIM-enabled commercial construction. Journal of construction engineering and management, 136 (4), 459-467.

Dossick, C.S. and Neff, G., 2011. Messy talk and clean technology: communication, problem solving and collaboration using building information modelling. Engineering project organization journal, 1 (2), 83-93.

Eckert, C., Stacey, M. and Earl, C., 2013. Formality in design communication. Architectural engineering and design management, 27 (2), 91-103.

Egan, J., 1998. Rethinking construction. London: Department of the Environment, Transport and the Regions.

Elmualim, A. and Gilder, J., 2014. BIM: innovation in design management, influence and challenges of implementation. Architectural engineering and design management, 10 (3-4), 183-199.

Emirbayer, M., 1997. Manifesto for a relational sociology. American journal of sociology, 103, 281-317.

Emmitt, S., 2011. Lean design management. Architectural engineering and design management, 7 (2), 67-69. 
Emmitt, S., 2016. The construction design manager-a rapidly evolving innovation. Architectural engineering and design management, 12 (2), 138-148.

Emmitt, S. and Ruikar, K., 2013. Collaborative design management. Abingdon: Routledge.

Eynon, J., 2013. CIOB design manager's handbook. Chichester: CIOB/WileyBlackwell.

Fischer, G., Giaccardi, E., Eden, H., Sugimoto, M. and Ye, Y., 2005. Beyond binary choices: integrating individual and social creativity. International journal of human-computer studies, 63 (4-5), 482-512.

Fosse, R. and Ballard, G., 2016. Lean design management with the Last Planner System. In: Proc. 24 $4^{\text {th }}$ Ann. Conf. of the Int'l. Group for Lean Construction, Boston, MA, USA, sect.4 pp. 33-42. Available at: <www.iglc.net>.

Gioia, D. A., Corley, K. G. and Hamilton, A. L., 2013. Seeking qualitative rigor in inductive research notes on the Gioia methodology. Organizational research methods, 16 (1), 1531.

Gubrium, J. F. and Holstein, J. A., 1997. The new language of qualitative method. New York, NY: Oxford University Press.

Heidegger, M. (1962), Being and time, New York: Harper and Row

Johansson, U. and Woodilla, J., 2011. A critical Scandinavian perspective on the paradigms dominating design management. In: R. Cooper, S. Junginger, \& T. Lockwood (Eds.), The Handbook of Design Management. Oxford, UK: Berg.

Jordan, B., 1996. Ethnographic workplace studies and CSCW. In: D. Shapiro, M. Tauber and R. Traunmüller (eds.), The design of computer supported cooperative work and groupware systems, Amsterdam: Elsevier Science B.V., $17-42$.

Kagioglou, M., Cooper, R. Aouad, G. and Sexton, M., 2000. Rethinking construction: the generic design and construction process protocol. Engineering, construction and architectural management, 7 (2), 141-153.

Kasali, A. and Nersessian, N. J., 2015. Architects in interdisciplinary contexts: Representational practices in healthcare design. Design studies, 41, 205-223.

Kent, D. C. and Becerik-Gerber, B., 2010. Understanding construction industry experience and attitudes toward integrated project delivery. Journal of construction engineering and management, 136 (8), 815-825. 
Kleinsmann, M. and Valkenburg, R., 2008. Barriers and enablers for creating shared understanding in co-design projects. Design studies, 29 (4), 369-386.

Kleinsmann, M., Buijs, J. and Valkenburg, R., 2010. Understanding the complexity of knowledge integration in collaborative new product development teams: A case study. Journal of engineering and technology management, 27 (1-2), 20-32.

Knotten, V., Svalestuen, F., Lædre, O. and Hansen, G.K., 2015. Organizational power in building design management. In: Proceedings of $23 \mathrm{rd}$ annual conference of the international group for lean construction. 29-31 July 2015, Perth, Australia. 763-772.

Koskela, L., Huovila, P. and Leinonen, J., 2002. Design management in building construction: from theory to practice. Journal of construction research, 3 (1), 116.

Kvan, T., 2000. Collaborative design: what is it? Automation in construction, 9 (4), 409415.

Langley, A.N.N., Smallman, C., Tsoukas, H. and van de Ven, A.H., 2013. Process studies of change in organization and management: unveiling temporality, activity, and flow. Academy of management journal, 56 (1), 1-13.

Latham, M. (1994). Constructing the team: joint review of procurement and contractual arrangements in the United Kingdom construction industry-final report. London: Department of the Environment.

Love, P.E.D., Irani, Z. and Edwards, D.J., 2004. A seamless supply chain management model for construction. Supply chain management: an international journal, 9 (1), $43-56$.

Luck, R., 2012a. 'Doing designing': on the practical analysis of design in practice. Design studies, 33 (6), 521-529.

Luck, R., 2012b. Kinds of seeing and spatial reasoning: examining user participation at an architectural design event. Design studies, 33 (6), 557-588.

McDonnell, J., 2009. Collaborative negotiation in design: a study of design conversations between architect and building users. CoDesign, 5 (1), 35-50.

McDonnell, J., and Lloyd, P., 2014. Beyond specification: A study of architect and client interaction. Design studies, 35 (4), 327-352.

Mills, K. L., 2017. Computer-supported cooperative work (CSCW). In: J. D. McDonald and M. Levine-Clark eds. Encyclopedia of library and information sciences, Boca Raton, FL: CRC Press, 1053-1067. 
Nicolini, D., 2012. Practice theory, work and organization. Oxford: Oxford University Press.

Nitithamyong, P. and Skibniewski, M.J., 2004. Web-based construction project management systems: how to make them successful? Automation in construction, 13 (4), 491-506.

Oak, A., 2009. Performing architecture: talking 'architect' and 'client' into being. CoDesign, 5 (1), 51-63.

Oak, A., 2012. 'You can argue it two ways': the collaborative management of a design dilemma. Design studies, 33 (6), 630-648.

Oh, M., Lee, J., Hong, S. W. and Jeong, Y., 2015. Integrated system for BIM-based collaborative design. Automation in construction, 58, 196-206.

Schön, D. A., 1983. The reflective practitioner. New York: Basic Books

Schutt, R. K. (2011). Investigating the social world: the process and practice of research. Thousand Oaks, CA: Pine Forge Press.

Sinclair, D., 2014. Design management: RIBA plan of work 2013 guide. London: RIBA Enterprises.

Stacey, R. 2001. Complex responsive processes in organizations: learning and knowledge creation. London: Routledge.

Stacey, R., 2003. Strategic management and organizational design - the challenge of complexity. 4th ed. Harlow: FT Prentice-Hall.

Stempfle, J. and Badke-Schaub, P., 2002. Thinking in design teams-an analysis of team communication. Design studies, 23 (5), 473-496.

Stumpf, S. C. and McDonnell, J. T., 2002. Talking about team framing: using argumentation to analyse and support experiential learning in early design episodes. Design studies, 23 (1), 5-23.

Thomas, W.I., 1923. The unadjusted girl. Boston, MA: Little, Brown and Company.

Tsoukas, H. and Chia, R., 2002. On organizational becoming: rethinking organizational change. Organization science, 13, 567-582.

Valkenburg, R.C., 1998. Shared understanding as a condition for team design. Automation in construction, 7 (2), 111-121.

Valkenburg, R. and Dorst K., 1998. The reflective practice of design teams. Design studies, 19 (3), 249-271

Van Amstel, F.M., Hartmann, T., van der Voort, M.C. and Dewulf, G.P., 2016. The social production of design space. Design studies, 46, 199-225. 
Van Dijk, J. and Van der Lugt, R., 2013. Scaffolds for design communication: Research through design of shared understanding in design meetings. AI EDAM, 27 (2), 121-131.

Weick K., 1995. Sensemaking in organisations. Thousand Oaks, CA: Sage

Weick, K. E., Sutcliffe, K. M. and Obstfeld, D., 2005. Organizing and the process of sensemaking. Organization science, 16 (4), 409-421.

Whyte, J., 2013. Beyond the computer: changing medium from digital to physical. Information and organization, 23 (1), 41-57.

Zerjav, V., 2012. Process and project level issues of design management in the built environment. Thesis (PhD). Vienna University of Technology.

Zerjav, V., 2015. Design boundary dynamics in infrastructure projects: Issues of resource allocation, path dependency and problem-solving. International journal of project management, 33 (8), 1768-1779.

Zerjav, V., Hartmann, T. and Achammer, C., 2013. Managing the process of interdisciplinary design: identifying, enforcing, and anticipating decisionmaking frames. Architectural engineering and design management, 9 (2), 121133. 